\title{
Exploiting the diazotization reaction of 4- minoacetophenone for Methyldopa determination.
}

\author{
Jwan A.AbdulSattar* \\ Received 8, January, 2013 \\ Accepted 4, March, 2013
}

\begin{abstract}
:
Based on the diazotization reaction of 4 -aminoacetophenone with sodium nitrite in acid medium to form diazonium salt, which was coupled with Methyldopa to form a violet reddish soluble azo dye with maximum absorbance at $560 \mathrm{~nm}$,a batch procedure had been developed for the estamination of Methyldopa. Under optimum experimental parameters affecting on the development and stability of the colored product, Beer's law obeyed in the range $(0.5-45) \mu \mathrm{g} \cdot \mathrm{ml}^{-1}$ with a correlation coefficient (0.9979). The proposed method was successfully applied to the determination of Methyldopa in either pure form and in commercial brands of pharmaceuticals, no interference was observed from common excipients in the formulations. The analytical results obtained by applying this method were in good agreement with labeled values.
\end{abstract}

Key words: Methyldopa, determination, diazotization, pharmaceutical preparation.

\section{Introduction:}

Due to the magnitude use of Methyldopa (MTD), chemically known as $\alpha$-methyl-3,4-dihydroxy phenyl alanine which is a catecholamine derivative widely used as an antihypertensive agent. The Methyldopa is a centrally acting $\alpha-2$ adrenoreceptor agonist, which reduces sympathetic tone and produces a fall in blood pressure [1].Besides, it is necessary for routine quality control in the analysis of produced medicines, thus there is an important demand for rapid and simple methods for the determination of methyldopa in pharmaceutical preparations. The official method reported in USP[2]describes a non aqueous titration for the assay of MTD,although this later one is kind of simple and being used in routine analysis laboratories, it is time consuming and very tedious. Several researches have been devoted to the development of new high performance alternative procedures for determinationof Methyldopa in medicines and/or biological specimens using different techniques such as Electrochemical [3-6], Chromatography[7-10],

Nanotechnology [11].How-ever these methods either requires sophisticated equitement;or involves procedures with rigorous control of the experimental conditions. Molecular absorption spectrophotometry is by far the instrumental technique of choice in industrial laboratories. Owning mainly to its simplicity, often demanding low cost equipment and lending itself to easy automation of trace analysis procedures, therefore a various number of UV-Visible spectrophotophotometric methods for

Methyldopa determination have been reported which involves the

*Department of Chemistry/College of Science/University of Al-Mustansiriyah. 
use of diverse chromogenic reagents such as: O-chloranil(O-CIN), Chloranilic acid (CIA) and Dichlorodicyanobenzoqu-inone (DDQ) [12], Vanadium[13],2,6-dichloroquinone -4chlorimide(DCQ[14],p-Chloranil[15]

tris(1,10phenanthroline[16],Molybdate [17,18],Salicylic acid[19],4-amino benzoic acid[20] and 3-amino pyridine[21].Nevertheless, most of the mentioned methods present some disadvantage and drawbacks such as long time for the color development[13],complex

procedure[17] and limited Beer's law range[14,18].

A vast number of aromatic
amines medicines such as:
Sulfamethoxazole[22],Pramipexole
Dihyochloride[23],Metronidazole[24], Ceftazidime[25] and Metoclopramide Hydrochloride and Dapsone[26] have been determined by the diazotization reaction, which is based on the conversion of free primary aryl amine into a diazonium salt by the reaction with nitrous acid; the salt then rapidly form an azo dye with a chromogenic reagent. The procedure requires the removal of excess nitrous acid by sulfamic acid, the stabilization of intermediary diazonium salt at low temperature and the expulsion of nitrogen bubbles [22].

The present paper describes the application of 4-amino acetophenone as an inexpensive new diazotization agent for the determination of MTD in medication. The method is based on the diazotization reaction of 4-amino acetophenone with sodium nitrite in hydrochloric acid medium; the formed diazonium salt is then coupled with MTD in sodium hydroxide medium to form a water soluble mono azo dye. This method does not need to get rid of excess sodium nitrite (by addition sulfamic acid or ammonium sulfamate) because of the low concentration of sodium nitrite used by adding equimolar solution of 4-amino acetophenone and sodium nitrite. The reaction product has been spectrophotometrically measured at $560 \mathrm{~nm}$.

\section{Material and Methods: Equipment:}

Shimadzu UV-VIS double beam spectrophotometer (VARIAN UV-Visible) with $1 \mathrm{~cm}$ matched quartz cells was used for all spectral measurements of the resulting solutions.

\section{Reagents and Chemicals:}

All chemicals were of analytical reagents grade.

1-Methyl dopa (MTD) stock standard solution $\left(1000 \mu \mathrm{g} . \mathrm{ml}^{-1}\right)$ was prepared by dissolving $0.0500 \mathrm{~g}$ of pure MTD (SDI) and made up to $50 \mathrm{ml}$ volumetric flask with distilled water. Working standard solutions were prepared by suitable dilution of the stock standard solution.

2-Hydrochloric acid solution (0.8 M) was prepared by diluting $6.68 \mathrm{ml}$ of $11.64 \mathrm{M}$ of concentrated hydrochloric acid (BDH) with distilled water in 100 $\mathrm{ml}$ volumetric flask.

3-Sodium hydroxide solution (0.5 M) was prepared by dissolving $1.0000 \mathrm{~g}$ of sodium hydroxide (BDH) in distilled water and diluting to the mark in $50 \mathrm{ml}$ volumetric flask.

4-4-amino acetophenone( $3 \mathrm{mM})$ solution was prepared by dissolving $0.0405 \mathrm{~g}$ of 4-amino acetophenon(BDH) in $5 \mathrm{ml}$ ethanol ,adding $20 \mathrm{ml}$ distilled water and finally the acidity was adjusted with 1 $\mathrm{ml}$ of $0.8 \mathrm{M}$ hydrochloric acid. This solution was frozen to zero degree using ice bath for $5 \mathrm{~min}$. To this solution equimolar of sodium nitrite was added with shaking for $10 \mathrm{~min}$., after that the azo solution was transferred to $100 \mathrm{ml}$ volumetric flask, 
diluted to the mark with distilled water and kept in the refrigerator.

\section{Procedures:}

\section{1-Assay of Pure Methyl dopa (MTD):}

Into a series of $25 \mathrm{ml}$ volumetric falsk, transfer increasing volumes of standard stock solution $\left(1000 \quad \mu \mathrm{g} \cdot \mathrm{ml}^{-1}\right) \quad$ containing (0.01-0.9) $\mathrm{ml}$ of Methyldopa to cover the range of calibration curve(0.545) $\mu \mathrm{g} . \mathrm{ml}^{-1}$ in a final volume of 25 $\mathrm{ml}$,to this solution add $4 \mathrm{ml}$ of azo 4 amino acetophenon,the solution was shacked thoroughly and $2 \mathrm{ml}$ of $0.5 \mathrm{M}$ $\mathrm{NaOH}$ was added. The contents were diluted to the mark with distilled water, after $15 \mathrm{~min}$. the absorbance of the azo dye was measured at $560 \mathrm{~nm}$ against the corresponding reagent blank.

\section{2-Assay of MTD in tablets dosage form:}

Ten tablets were finely weight, ground and powdered. A quality corresponding to the weight of one tablet $(250 \mathrm{mg})$ was carefully weighted and made up to $100 \mathrm{ml}$ with distilled water. The resultant solution was filtered and diluted to 3 different concentrations which were analyzed in five replicate as described under the assay of pure Methyldopa (MTD0.

\section{Result and Discussion: Preliminary Studies}

The proposed method involves diazotization of the 4-amino acetophenone with sodium nitrite in hydrochloric acid medium to form diazonium salt, which on coupling with Methyldopa in sodium hydroxide medium yielding a water-soluble azo dye. The visible spectrum (Fig.1) of the yielded reaction product demonstrates that the best analytical wavelength is located at $560 \mathrm{~nm}$, which has a negligible absorbance at reagent blank at the corresponding $\lambda_{\max }$.

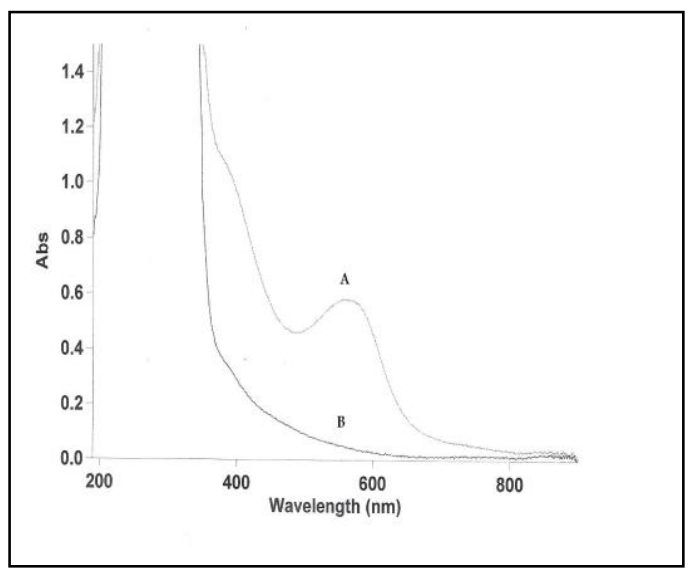

Fig (1): Absorption spectra of azo dye against reagent blank (A) and agent blank against distilled water(B).

\section{Optimization conditions:}

The optimum reaction conditions have been established by varying the factors one at a time and keeping the other parameters fixed and observing the effects of the product on the adsorbance.These factors include the $\mathrm{NaOH}, 4$-amino acetophenone, $\mathrm{HCl}$ volumes, time and addition sequence.

The effect of different volumes $(0.5-4) \mathrm{ml}$ of $(0.5 \mathrm{M})$ Sodium hydroxide, (1-7) $\mathrm{ml}$ 4-amino acetophenone $(3 \mathrm{mM})$ and $(0.5-3) \mathrm{ml}$ Hydrochloric acid $(0.8 \mathrm{M})$ were used for color development. Fig (2) depict the obtained results showing that $(2 \mathrm{ml})$ of $\mathrm{NaOH}(0.5 \mathrm{M}),(4 \mathrm{ml})$ 4-amino acetophenone $(3 \mathrm{mM})$ and $(1 \mathrm{ml})$ of $\mathrm{HCl}(0.8 \mathrm{M})$ were efficient for accurate reproducible volumes use. 


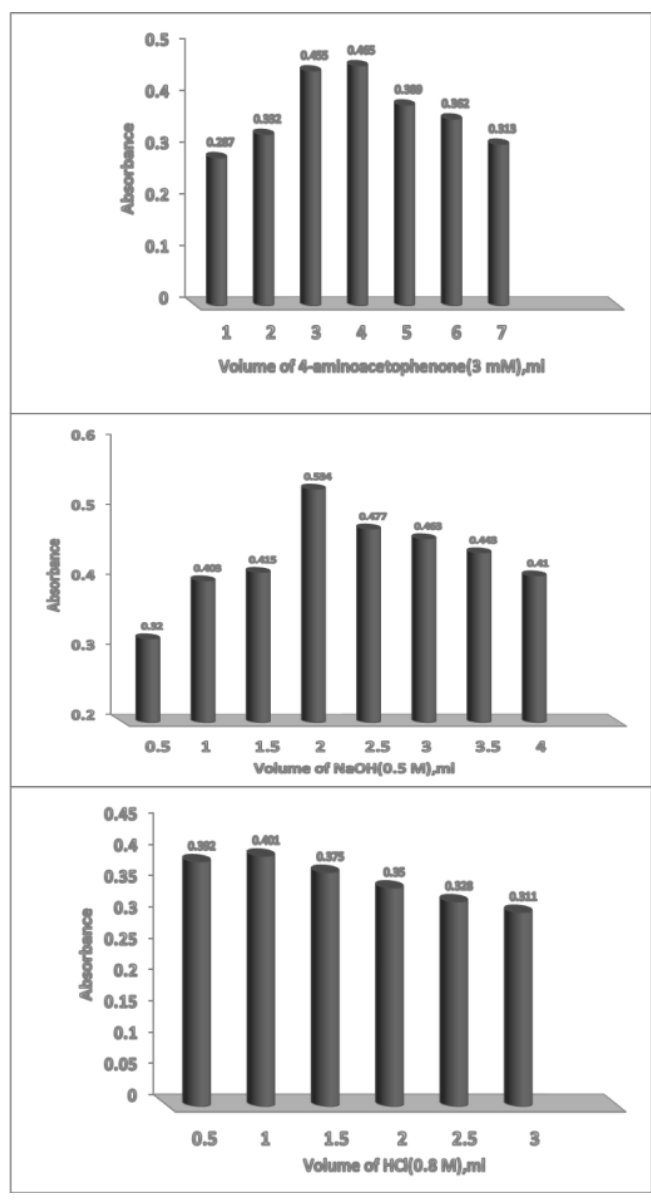

Fig (2): Optimum conditions for determination of Methyldopa

Different diazotization reaction times were tried in the proposed experiments. It was shown from Fig (3) that the absorbance was maximum and stable within (15 min.) min.Thus 15 min. was adopted as the diazotization reaction time.

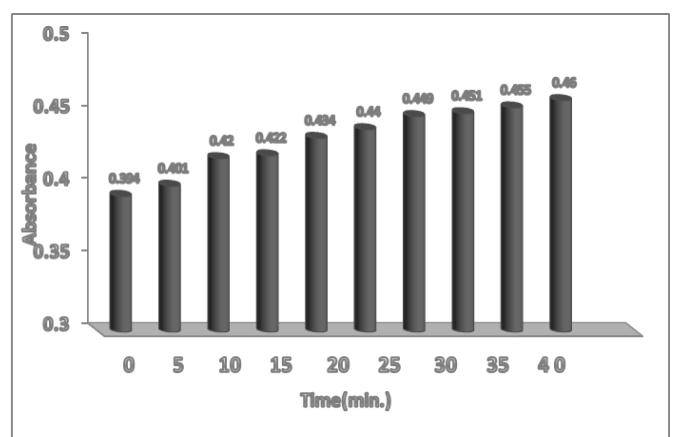

Fig (3): Effect of time.

Acceleration of color intensity was applied by varying the addition sequence of the drug (MTD), base
$(\mathrm{NaOH})$ and the reagent(4-amino acetophenone).Best absorption values was achieved by adopting the following sequence (Drug+ Reagent+ Base).Fig(4).

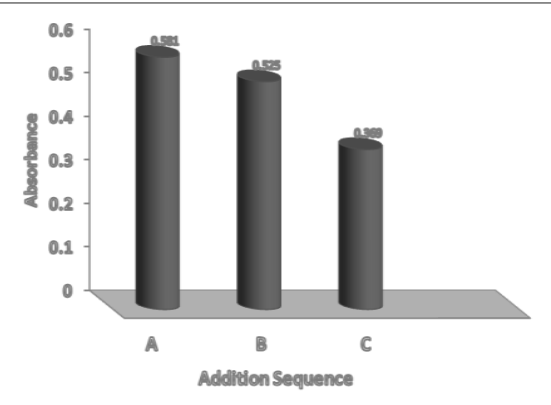

Fig (4): Sequence effect. $A=$ Drug+Azo reagent+Base $B=A z o$ reagent + Base + Drug $\mathrm{C}=$ Base + Drug + azo reagent

\section{Study of the dye:}

The composition of the formed complex had been established using Mole ratio method which was based on the measurement of series of solution in which increased volumes(0.5-4) $\mathrm{ml}$ of $(3 \mathrm{mM})$ diazonium reagent were added to a fixed volume(1) $\mathrm{ml}$ of(3 $\mathrm{mM}$ ) Methyldopa, under optimum conditions mentioned in the analytical procedure, the results obtained in Fig(5) indicate that 1:1 azo dye was formed between Methyldopa(D) and diazonium azo reagent( $\mathrm{R})$. The probable reaction path might be written as follow:

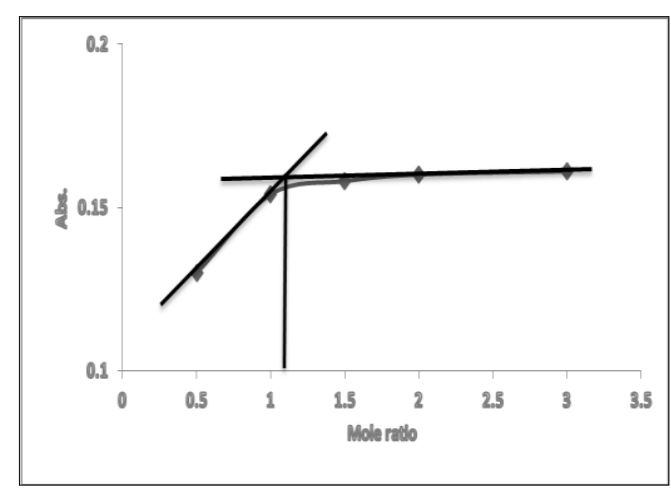

Fig (5): mole ratio plot. 


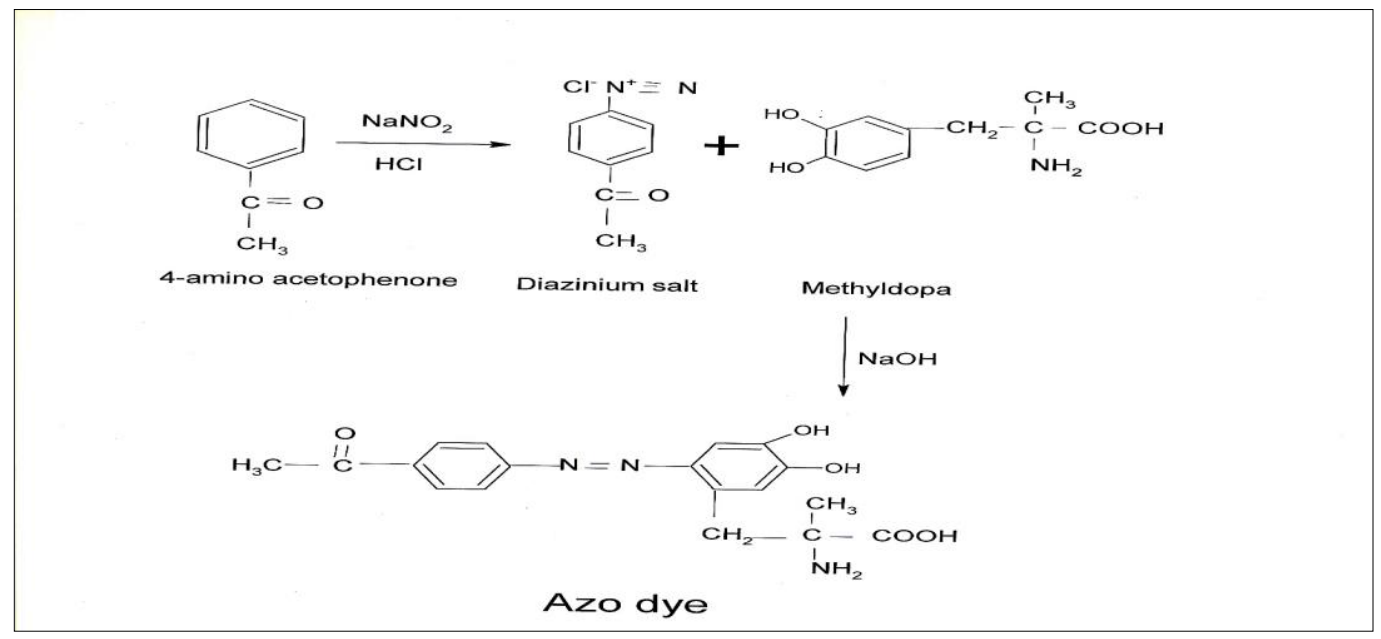

Scheme (1): Reaction path.

The product formed was soluble in water. The apparent stability constant was calculated by comparing the absorbance of a solution containing stoichiometric amount of MTD (3)mM $\left(\mathrm{A}_{\mathrm{s}}\right)$ that of a solution containing a five-fold excess of Diazionium reagent $\left(\mathrm{A}_{\mathrm{m}}\right)$ and according to analytical procedure. The stability constant $(\mathrm{K})[27]\left[\mathrm{K}=(1-\alpha) / \alpha^{2} \mathrm{C} ; \alpha=\left(\mathrm{A}_{\mathrm{m}^{-}}\right.\right.$ $\left.\left.\mathrm{A}_{\mathrm{s}}\right) / \mathrm{A}_{\mathrm{m}} ; \mathrm{A}_{\mathrm{m}}=0.11, \mathrm{~A}_{\mathrm{s}}=0.16, \mathrm{C}=3 \times 10^{-3} \mathrm{M}\right]$ of the product in water under the described experimental of conditions was $2.0 \times 10^{3} \mathrm{~L}^{\mathrm{mol}}{ }^{-1}$.

\section{Figures of merits:}

For proposed method, the calibration graph was obtained by the procedure described previous and a series of standard solutions was analyzed to test the linearity. The molar absorptivity, the sandell's sensitivity, the slope, the intercept and correction coefficient were evaluated by a least squares regression analysis and were included in Table (1).

Statistical evaluation of regression line gave the values of standard deviations for residuals(Sy/x), slop (Sa) and intercept(Sb) at 95\% confidence are demonstrated in Table(1)These small figures point out to the high precision of the proposed method, also the limit of detection(LOD) and limit of
quantitative(LOQ) were calculated and shown in the same table.

|Table (1): Data for calibration graph for MTD.

\begin{tabular}{|c|c|}
\hline Parameters & Values \\
\hline Correlation coefficient, $\mathrm{r}^{2}$ & 0.9979 \\
\hline $\begin{array}{c}\text { Test for a significant } \\
\text { correlation (at confidence } \\
\text { level 95\%). }\end{array}$ & 2.262 \\
\hline Regression equation & $\mathrm{Y}=0.0077 \mathrm{x}+0.0233$ \\
\hline Slope, $\mathrm{b}\left(\mathrm{ml} . \mu \mathrm{g}^{-1}\right)$ & $7.7 \times 10^{-3}$ \\
\hline Intercept, a & $2.33 \times 10^{-2}$ \\
\hline Conf. limit for slope $b \pm t_{s b}$ & $0.0077 \pm 0.000259$ \\
\hline $\begin{array}{l}\text { Conf. Limit for intercept } \\
\qquad \mathrm{a} \pm \mathrm{t}_{\mathrm{sa}}\end{array}$ & $0.0233 \pm 0.017721$ \\
\hline $\begin{array}{l}\text { Standard deviation of the } \\
\text { residuals, } S_{y / x}\end{array}$ & $5.6929 \times 10^{-3}$ \\
\hline $\begin{array}{l}\text { Standard deviation of the } \\
\text { slop, } S_{b}\end{array}$ & $1.1472 \times 10^{-4}$ \\
\hline $\begin{array}{l}\text { Standard deviation of the } \\
\text { intercept, } S_{a}\end{array}$ & $7.8346 \times 10^{-3}$ \\
\hline $\begin{array}{l}\text { Conf. limit conc. } \mu \mathrm{g} \cdot \mathrm{ml}^{-1} \\
\text { 95\% C.I. }\end{array}$ & $14.96 \pm 0.141261$ \\
\hline Conf. limit Abs. 95\% C.I. & $0.138 \pm 0.001496$ \\
\hline Linearity range $\left(\mu \mathrm{g} \cdot \mathrm{ml}^{-1}\right)$ & $0.5-45$ \\
\hline $\begin{array}{l}\text { Molar absorptivity, } \\
\varepsilon\left(1 . \mathrm{mol}^{-1} \cdot \mathrm{cm}^{-1}\right)\end{array}$ & $1.0434 \times 10^{4}$ \\
\hline $\begin{array}{l}\text { Sandell's sensitivity, } \\
\mathrm{S}\left(\mu \mathrm{g} . \mathrm{ml}^{-1}\right)\end{array}$ & $2.0241 \times 10^{-2}$ \\
\hline $\begin{array}{l}\text { Limit of detection, } \\
\text { LOD }\left(\mu \mathrm{g} . \mathrm{ml}^{-1}\right)\end{array}$ & $1.1364 \times 10^{-1}$ \\
\hline $\begin{array}{c}\text { Limit of quantification, } \\
\operatorname{LOQ}\left(\mu \mathrm{g} . \mathrm{ml}^{-1}\right)\end{array}$ & $7.3933 \times 10^{-1}$ \\
\hline
\end{tabular}

Accuracy and Precision of the proposed method.

The accuracy and precision of the proposed method were tested by analyzing four replicate of MTD by proposed spectrophotometric method for three different concentrations of 
MTD.The low values of Erel.\% which are summarized in Table(2) indicate to the high accuracy and precision of the proposed method.

Table (2): Accuracy and precision of the proposed method.

\begin{tabular}{|c|c|c|c|}
\hline \multicolumn{2}{|c|}{ Conc.of MTD $\mu$ g.ml ${ }^{-1}$} & \multirow{2}{*}{ E \% } & \multirow{2}{*}{ Rec.\% } \\
\cline { 1 - 2 } Present & Found & & \\
\hline 15.000 & 14.960 & -0.266 & 99.733 \\
\hline 35.000 & 34.875 & -0.357 & 99.642 \\
\hline 45.000 & 44.922 & -0.172 & 99.827 \\
\hline
\end{tabular}

\section{Pharmaceutical Applications:}

In order to demonstrate the applicability of the proposed method for the determination of Methyldopa, the method was successfully applied to the analysis of different pharmaceutical preparation containing MTD and results are summarized in Table (3).For all preparations examined, the assay results of proposed method were in good agreement with the labeled content.

Table (3): Application of the proposed method for the determination of MTD in pharmaceutical preparations.

\begin{tabular}{|c|c|c|c|c|}
\hline \multirow[t]{2}{*}{$\begin{array}{c}\text { Pharmaceuti-cal } \\
\text { preparation }\end{array}$} & \multicolumn{2}{|c|}{$\begin{array}{l}\text { Conc.of MTD } \\
, \mu g . \mathrm{ml}^{-1}\end{array}$} & \multirow[t]{2}{*}{ E \% } & \multirow[t]{2}{*}{ Rec.\% } \\
\hline & Present & Found & & \\
\hline \multirow{3}{*}{$\begin{array}{c}\text { ALDOSAM }(250 \\
\mathrm{mg})\end{array}$} & 15.000 & 14.922 & -0.519 & 99.480 \\
\hline & 35.000 & 34.854 & -0.421 & 99.57 \\
\hline & 45.000 & 45.025 & +0.057 & 100.057 \\
\hline \multirow{3}{*}{$\begin{array}{c}\text { ALDOMETHYL(250 } \\
\mathrm{mg})\end{array}$} & 15.000 & 14.896 & -0.692 & 99.307 \\
\hline & 35.000 & 34.805 & -0.556 & 99.443 \\
\hline & 45.000 & 44.935 & -0.144 & 99.855 \\
\hline
\end{tabular}

\section{Conclusion:}

The developed methodology is very adequate for the determination of methyldopa in aqueous solution and in pharmaceutical preparation samples at a concentration level of traces(ppm) and without requiring any previous separation step nor a temperature or $\mathrm{pH}$ control.Morever the proposed methods are very economical when compared to other methods such as those based on the use of HPLC .

\section{Reference}

1-Hoffman, B.B,Lefkowitz, R.S,in: A.G. Gilman, J.G.Hardman, L.E. Limbird, P. B. Molinoff, R.W.Ruddon (Eds.).1996."The pharmacological Basis of Therapeutics",MacGrow-Hill,New York,9th ed.,Chapter 12.

2-The United states Pharmacopeia, 2000.The United States Pharmacopoeial Convention: Rockville, MD, $24^{\text {th }}$ ed.

3-Saeed, S.,Reyhaneh-Sadat, S. and Zahra, K. 2011.Sensitive Electrochemical Sensor for Determination of Methyldopa Based on Polypyrrole/Carbon Nanoparticle Composite Thin Film Made by In Situ Electropolymerization, Electr. analysis.23(9):2248-2254.

4-Mohammad, B. G. and Masoud, A.2009. Preparation of Polypyrrole/Nuclear Fast Red Films on Gold Electrode and Its application on the Electrocatalytic Determination of Methyl-dopa and Ascorbic Acid ,Electranalysis. 21(22):2461-2467.

5-Norouzi,P. Ganjali,M.R. hahtaheri, S.J. Dinarvand, R. and amzehpoor, A. 2009. Monitoring of Methyldopa by Fast Fourier Transform Continuous Cyclic Voltammetry at Gold Microelectrode ,Chin. J. Chem.27(4):732-738. 
6-Azhar Ali, S. and Sami, M. A.2005. Cyclic Voltammetric Study Of $\alpha$ Methyldopa At Carbon Paste Electrode, Pak. J. Pharm. Sci.18(1):6-17.

7-Valizadeh, H.,Nemati, M.,HallajNezhadi, S.,Ansarin, M. and Zakeri-Milani, P.2010. Single dose bioequivalence study of alphmethyldopa tablet formulations using a modified HPLC method, Arzneimittelforschung. 60(10):607-11.

8-Chiara, M.,Erica, B.,Lucia, T.,Brunetta, P.,Iiaria, C.,Roberto, P. and Roberto, G.2008. Simultaneous determination of serum concentrations of Levodopa, dopamine,3-Omethyldopa and $\alpha$-methyldopa by HPLC, Bio. and Pharm .62(4):253-258.

9-Gholamreza, B.,Amir, K. and Shahla, M.2006.A rapid high performance liquid chromatographic determination of methyldopa in human serum with fluorescence detection and alumina extraction:Application to a bioequivalence study, J. Chromatog.B.832(2):197-201.

10-Wang, C.,Wang, Z.,Han, D.,Hu, Y.,Zhao, J.,Yang, X. and Song, S.2006.Simultaneous determination of levodopa and methyldopa in human serum by capillary electrophoresis, Chin. J. Chromatog.24(4):389-91.

11-Ali, M.,Abdolmajid, B.,Rassoul, D.,Jalil, B.,Fatemeh, A. and Ali,A.2008. Bioelectrocatalysis of Methyldopa by Adsobed Tyrosine on the surface of Modified Glassy Carbon with Carbon Nanotubes, Int.J. Electrochem. Sci. 3:12481257,

12-Shama, K.,Sharma, SP and Lahiri, SC.2012.Spectrophotometric,Fouri er transform infrared spectroscopic and theoretical studies of the charge-transfer complexes between methyldopa[(S)-2 amino3-(3,4-dihydroxyphenyl)-2-methyl propanoic acid] and the acceptors (chloranilic acid,o-chloranil and dichlorodicyanoben-zoquinone) in acetonitrile and their thermodynamic properties, Spectro chem Acta A Mol Biomol Spectrosc. 15(92):212-224.

13-Padmarajaiah, N., Ashwinee, K.,Anantharaman, S.,Naef, G.and Avinask, K.2011. Spectrophotometric Determination of Catecholamine Using Vanadium And Eriochrome Cyanine R, Quim.Nova.34(3):1-4.

14-E.A., Gadkariem,K.E.E., Ibrahim, N.A.A., Kamil,M.E.M. ,Haga and H.A., El-Obeid.2009. A new spectrophotometric method for the determination of methyldopa, Saudi Pharm. J. 17(4): 289-293.

15- Gotardo, M.A.,Lima,L.S., R. Sequinel, Rufino J.L., Pezza,L. and Pezza, H.R. 2008. A simple spectrophotometric method for the determination of methyldopa using p-chloranil in the presence of hydrogen peroxide, Ecl. Quim. 33(3):7-12.

16-M., Chamsaz,A., Safavi and J., Fadaee.2007.Simultaneous kinetic spectrophotometric determination of carbidopa,levodopa and methyldopa in the presence of citrate with the aid of multivariate calibration and artificial neural networks, Analytica Chimica Acta.603:140-146.

17-Paulo R.,Leonardo, P.and Helena, R.P.2006.Determination of Methyldopa in Pharmaceutical Formulations by combined Spot Test-Diffuse Reflectance spectroscopy, J. Braz. Chem. Soc.17(4):674-679.

18-P.R.S., Riberiro,L., Pezza and H.R., Pezza.2005.Spectrophotometric determination of methyldopa in 
pharmaceutical formulations, Ecl.Quim.30(3):23-28.

19-Tubino, M.,Batista, D. and Rodrigues, J.A.2006.Kinetic Method for the Determination of $\alpha$-Methyldopa in Pharmaceutical Preparations:analytical Proceudure and Reaction Mechanism Considerations, Analytic.

Lett.39(2):327-339.

20-Tayyebeh, M.,Abbas, A.,Lida, K.and Massoumeh, M.2006. Spectrophotomrtic Determination of Catecholamines based on their Oxidation Reaction Followed with 4-Aminobenzoic Acid,J. Braz. Chem. Soc.17(7):1259-1265.

21-Mouyed, Q.Al-Abachi and Muneer, A.Al-Daamy.2005.Determination of catechol Amine Drug in Pharmaceutical preparation via Oxidative Coupling Reaction with 3-Amino Pyridine and Sodium Periodate, National J. Chem. 18:226-234.

22-Raghad, S. and Wasan, A. AlUzri.2011.Spectrophotometric

Method for Determination of Sulfamethoxazole in Pharmaceutical Preparations by Diazotization-Coupling Reaction, J. Al-Nahrain Univ...14(3):9-16.
23-B.M., Gurupadayya,V., Vishwajith and N., Srujana. 2009. Spectrophotometric Methods for the Estimation of Pramipexole Dihydrochloride Pharmaceutical Formulations, sWorld J. Chem. 4(2):157-160.

24-P. Thulasamma and P. Venkateswarlu.2009.Spectrophoto metric Method for the Determination of Metronidazole in Pharmaceutical Pure and Dosage Forms, Rasayan J. Chem. 2(4),865868.

25-Basavaraj, H.,Bennikallu, H.and Mruthyun, J.2008.Development and validation of spectrophotometric methods for determination of ceftazidine in pharmaceutical dosage form, Acta Pharm. 58:275-285.

26-Hosakere, D. R.and Malligere,A. V. 2006. Sensitive Spectrophotometric determination of Metoclopramide Hydrocloride and Dapsone in Bulk Sample and Dosage Forms,Sci. Asia.32:319321

27-M.Q.,Al-Abachi and T.S.,AlGhabsha.1983.Fundamentals of Analytical Chemistry.Press of Mousl University, Mousl, , pp 346.

\section{استكثاف تفاعل الازوتة ل4-امينو اسيتوفينون لتقدير عقار المثيل دوبا}

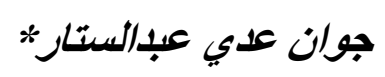

*قسم الكيمياء/كلية العلوم/الجامعة المستنصرية.

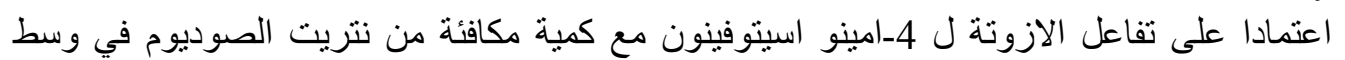

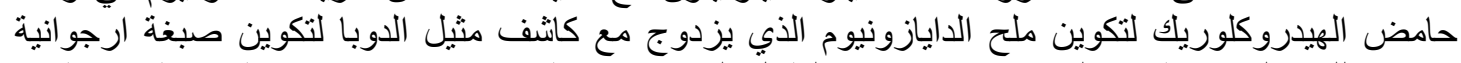

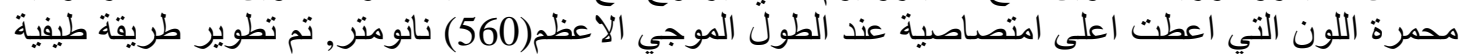

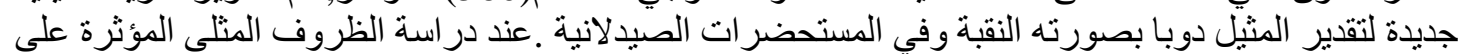

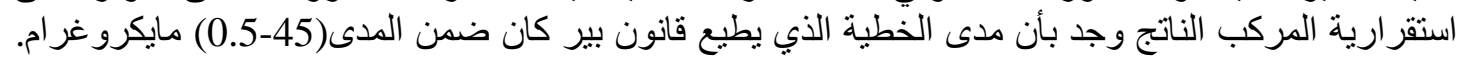

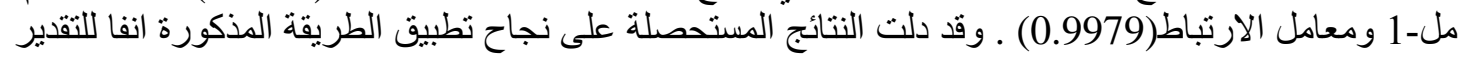
الطيفي الكمي لدواء المثيل دوبا في المستحضر ات الصنيل الصيدلانية. 